\title{
PROGRAMAS DE PARTICIPAÇÃO NOS RESULTADOS: UM ESTUDO EM EMPRESAS MÉDIAS
}

Marilsa Sá Rodrigues Tadeucci 1

\section{Resumo}

O bjetiva verificar se a implantação dos programas de participação nos resultados trouxe melhorias para a administração participativa das empresas de porte médio da região do Vale do Paraíba, no estado de São Paulo. A pesquisa é de natureza qualitativa e quantitativa e realizada em três etapas. A primeira foi um levantamento, via telefone, para identificar as empresas que comporiam a amostra; a segunda foi realizada por meio de entrevistas com os responsáveis pelos programas, gerentes de produção e os dirigentes sindicais representativos das orientações predominantes na região e, finalmente, a aplicação de questionário em 274 funcionários de produção. 0 s dados foram submetidos a tratamento estatístico, utilizando-se análises descritivas simples, multivariadas, inferencial e correlacional. Conclui-se que os programas de participação nos resultados estão modificando a forma de gestão nas empresas, tornando-as mais participativas. As variáveis que interferem nesse processo são as características de cada empresa, idade dos respondentes, escolaridade, tempo de casa e gênero. A orientação sindical pode interferir na escolha de programas de metas ou valores fixos. Houve melhora na comunicação e no relacionamento entre o grupo de trabalho, maior envolvimento e comprometimento dos empregados com os programas de participação nos resultados e, conseqüentemente, com as metas negociadas entre empresa e sindicato.

Palavras-chave: Participação nos resultados; Administração participativa; Participação.

\section{PROGRAMS OF PARTICIPATION IN THE RESULTS: A STUDY IN AVERAGE COMPANIES}

\begin{abstract}
The objective of this study is to estimate whether the implementation of results participation programs has brought improvements to the participatory management of medium sized companies located in the region of Vale do Paraíba, State of São Paulo. The survey has considered both qualitative and quantitative methods, performed in three stages. The first stage was a telephone inquiry in order to identify the companies that would constitute the sample; the second was carried out by means of interviews with program leaders, production managers, and the region predominant orientation labor union representatives; and finally a questionnaire fill-out for 274 production employees. Data was submitted to statistical treatment by means of simple, multi-variational, inferential and co relational analysis. It was realized that the results participation programs are changing the management way of the companies, making them more participative. The variables interfering with such a process had to do with each company's characteristic, the age of respondents, their schooling, time of employment and gender. The trade union orientation can interfere with the choice of goal programs or preset values. Communication has improved, as well as the relationship amongst those in the work team; a higher level of employees' involvement and commitment to results participation programs and consequently to the goals negotiated between companies and labor unions was noticed.
\end{abstract}

Key words: Participation in the results; Participative administration; Participation.

\section{INTRODUÇÃO}

Os programas de participação nos lucros e resultados, assim como outras formas de participação, são criados com o objetivo de diminuir os conflitos, aumentar a participação dos empregados no trabalho e, conseqüentemente, aumentar a competitividade das empresas. $(1)$

A maioria dos países classificados como "emergentes" neces- sitam manter uma estabilidade econômica e social para garantir o seu desenvolvimento Para alcançar esses objetivos, torna-se necessário aumentar a competitividade das empresas, possibilitando maior lucratividade, estabilidade de mercado e manutenção e ou elevação dos níveis de emprego.

$\mathrm{Na}$ procura desse desenvolvimento, 0 governo brasileiro editou, em 1994, Medida

1 Doutor, Universidade de Taubaté, Universidade Presbiteriana Mackenzie 
Provisória, de número 794, que versava sobre a implantação de programas de participação nos lucros e ou resultados nas empresas.

No artigo 10 desta regulamentação estava explicitado o seu objetivo: "instrumento de integração entre capital e o trabalho e como incentivo à produtividade".

A Medida Provisória prevê a utilização de uma das formas (Participação nos Lucros ou Participação nos Resultados) ou das duas, conjuntamente. A adoção dos programas limitada à participação nos lucros exige maior controle contábil financeiro, além da disponibilidade das empresas em divulgar os seus números, e reduz a possibilidade da participação direta dos empregados para o alcance dos resultados financeiros. A participação nos resultados tem melhor aceitação por parte das empresas e de alguns sindicatos. Exige a definição clara de indicadores e metas, para promover maior participação dos empregados.

Pesquisas realizadas pelo Departamento Intersindical de Estatísticas e Estudos SócioEconômicos(2) e pela Fundação Instituto de Pesquisas(3) revelam, como resultados da Medida Provisória de 1994, que os sindicatos passaram a negociar cada vez mais, com as empresas, programas de participação nos lucros e resultados.

Os resultados divulgados, principalmente pela FIPE, em 1998, demonstram que apenas 3\% das empresas adotam unicamente o sistema de PL. As que empregam o sistema de PL e PR correspondem, a $19 \%$ das empresas pesquisadas, e $69 \%$ optaram pela participação nos resultados. Devido à obrigatoriedade imposta pela Medida Provisória, as empresas implantaram os programas por iniciativa própria ou por pressão dos sindicatos.

Em face de uma elevada adoção de PLR pelas empresas e pressões no meio político para limitar o uso de Medidas Provisórias como recurso legal, o governo brasileiro transformou a Medida Provisória em lei, em de dezembro de 2000 (Lei no 10.101).

Este trabalho tem como principal finalidade conhecer a percepção dos empregados e sindicalistas sobre os programas de participação nos resultados quanto às estratégias de negociação utilizadas e o grau de credibilidade nesse tipo de representação, circunscrito às médias empresas da região do Vale do Paraíba no estado de São Paulo.

A importância desses programas não pode ser subestimada, na gestão das empresas, tampouco nas estratégias sindicais. A opinião dos empregados, que na situação são beneficiados ou não por essas políticas e estratégias, torna-se de fundamental importância para um re-planejamento e re-direcionamento das mesmas. Somente quando os funcionários se sentirem participantes do processo ou devidamente representados será possível considerar que os programas de participação nos resultados estão atingindo os seus objetivos.

\section{CON SIDERAÇÕES TEÓRICAS}

\section{Caracterização da Participação dos Lucros e Resultados}

As origens dos Programas de Participação nos Lucros e Resultados das empresas estão nos conceitos gerais de participação no trabalho, que pode ser concebida como uma forma de remuneração variável.

O s Programas de Participação nos Lucros e Resultados são abrangentes e envolvem vários interlocutores, como o governo que, os cria, as empresas, que os adotam, os sindicatos que os negociam, e os empregados, que se esforçam para atingir os resultados e, conseqüentemente, se beneficiam.

A compreensão desse tipo de estratégia pressupõe conhecimentos sobre participação no trabalho, administração e gerência participativa, remuneração variável, e sobre os fundamentos, as origens e os aspectos legais dos programas de Participação nos Lucros e Resultados.

\section{Objetivos da PLR}

O s objetivos da implementação do PLR são aqui analisados a partir das perspectivas dos agentes envolvidos, ou seja: governo, empresa, empregado e sindicatos.

\section{a - Governo}

Sob a óptica do governo, as políticas referentes ao PLR têm-se limitado, em quase todo mundo, à sua indução por meio de incentivos fiscais associado a um conjunto de objetivos como a diminuição do conflito entre capital e trabalho, redução dos efeitos de períodos econômicos recessivos sobre o nível de emprego pela criação de uma remuneração flexível capaz de se ajustar a condições adversas de mercado, aumento da poupança nacional, e como incentivo ao aumento da produtividade do trabalho.

No caso brasileiro, além desses objetivos de caráter geral, a PLR tem como objetivos facilitar a transição de uma política salarial indexada para um modelo baseado em crescimento e produtividade.

Para Gonçalves(4) seria a transformação dos resíduos inflacionários, não incorporados automaticamente aos salários, em valores negociados a título de alcance de metas predefinidas. 0 autor ressalta ainda que a implementação do PLR provoca efeitos sobre o crescimento econômico uma vez que passa a representar um acréscimo real de salário para o trabalhador sem repasse para o preço dos produtos e que somente ocorrerá se houver um aumento de produtividade de trabalho real nas empresas. 


\section{b - Empresas}

Para as empresas, a implementação do PLR está associada ao desenvolvimento de programas de qualidade e produtividade,(5) pois garante a participação dos trabalhadores por atuar como forma de recompensa aumentando a motivação. Diminuir absenteísmo e perdas, economizar insumos, amenizar o conflito capital e trabalho, diminuir as pressões por ganhos reais de salário e diminuir as interferências sindicais são alguns outros importantes objetivos que justificam o PLR para os empresários.(4)

\section{C - Empregados}

Para os funcionários, o programa de participação nos lucros e resultados pode oferecer, além dos ganhos materiais envolvidos, a possibilidade de maior participação na gestão, através do maior controle das atividades ligadas ao processo produtivo e questões mais amplas no âmbito das ações da empresa. (4)

\section{d - Sindicatos}

Para os sindicatos, a negociação do PLR deve ser vista como um dos muitos instrumentos contraditórios que podem ser utilizados para uma construção de consciência de classe. Não deve servir para os propósitos de uma parceria inconsciente e desmobilizadora (6)

Os sindicatos, no mundo todo sempre se opuseram ao programa de participação nos lucros e resultados por considerar uma forma de enfraquecimento da classe trabalhadora, e como observamos nos resultados das pesquisas americanas o programa tinha maior sucesso nas empresas onde 0 índice de sindicalização era inferior. Para o Sindicato dos Metalúrgicos do $A B C$ e, para a grande maioria dos sindicatos ligados à CUT, se a participação nos lucros e resultados for trabalhada de forma responsável e conscientizadora será um instrumento para acumular forças e se constituirá em avanço no grau de organização e mobilização; buscando os objetivos maiores dos sindicatos que são à busca da democracia, condições sociais mais justas e que 0 progresso econômico seja atingido com respeito aos direitos dos cidadãos.(6)

\section{A PESQUISA}

Esta pesquisa de nível exploratório e descritivo foi estruturada em três etapas interdependentes. $\mathrm{N}$ a primeira foram realizadas entrevistas estruturadas, por telefone, com a finalidade de identificar as empresas que possuíam programas de PPR (Participação nos Resultados), para delimitação da amostra. $\mathrm{Na}$ segunda etapa foram entrevistados os responsáveis pelos programas das empresas pré-selecionadas, gerentes de produção e diretores sindicais representantes das categorias de trabalhadores das empresas em estudo. Este estudo, de natureza qualitativa, forneceu subsídios para a elaboração de um questionário, que compôs a terceira e última etapa da pesquisa. A aplicação do questionário resultou em uma tabulação, e a análise quantitativa que permitiu maior conhecimento dos fatores que interferem nos objetivos e problemas levantados por este trabalho.
Nesse artigo, por serem enfatizadas as ações do sindicato e a percepção dos empregados serão ressaltados os procedimentos para obtenção destes dados.

\section{Roteiro de Entrevista com os Sindicatos}

Este roteiro foi basicamente elaborado a partir da revisão da literatura, principalmente a voltada ao material produzido pelo Sindicato dos Metalúrgicos do $A B C$, DIEESE, e das hipóteses levantadas na pesquisa telefônica. Foram formuladas dezessete questões voltadas aos seguintes objetivos: conhecer a importância do sindicato na criação dos programas de PLR, verificar se existe alguma preferência por programas baseados em metas ou em lucros, analisar a visão do sindicato sobre os motivos que levam as empresas a optarem por lucros ou resultados, observar quais os indicadores sugeridos pelo sindicato, o processo de negociação de metas e os critérios para o estabelecimento do valor relativo ao lucro. Alem destes, verificar como tem sido a implantação dos programas na região, quais as vantagens e desvantagens que estes programas trouxeram para os sindicatos, empresas e funcionários, se a implantação dos programas trouxe mudanças na mentalidade dos empresários, gerentes e funcionários, quais as diferenças de negociação de empresas de diferentes portes, quais são os principais objetivos do sindicato quando negociam os programas de PLR e quando o sindicato considera que a negociação foi um sucesso.

\section{Q uestionário aplicado nos empregados}

Com base nos dados encontrados nas etapas anteriores, foram formuladas 52 frases, com o objetivo de contemplar todos os aspectos considerados importantes para avaliação, além de dados que caracterizam a amostra, como escolaridade, tempo de casa, idade, sexo e cargo.

\section{RESULTADOS}

$\mathrm{Na}$ pesquisa telefônica foram contatadas as 81 empresas de porte médio, conforme cadastro FIESP, destas apenas 40 se dispuseram a responder a pesquisa.

Todas tem programas de PLR, estão situadas entre as cidades de Jacareí e C ruzeiro, 0 tempo de implantação do programa varia de 7 (duas empresas) a apenas uma empresa, sendo que o tempo médio de implantação são três anos. Os programas variam entre proposta de metas e metas e valor fixo. Esta diferença deve- 
se pela filiação sindical, as empresas químicas ou ligadas à orientação política mais radical estabelecem um valor fixo no acordo coletivo de trabalho. Os sindicatos predominantes são químicos, metalúrgicos e têxteis.
A seguir será apresentado o quadro síntese das entrevistas realizadas com três dirigentes sindicais ligados a orientações políticas/ ideológicas distintas apesar de todos estarem agregados na CUT (Central Única dos Trabalhadores).

\begin{tabular}{|c|c|c|c|}
\hline CATEGORIAS & SINDICATO ARTICULAÇÃO & SINDICATO PSTU & SINDICATO NEUTRO \\
\hline $\begin{array}{l}\text { PAPEL DO } \\
\text { SIN DICATO }\end{array}$ & $\begin{array}{l}\text { Discussão da previsão de lucro } \\
\text { para transformar em parcela, } \\
\text { que é dividida entre os } \\
\text { trabalhadores. }\end{array}$ & $\begin{array}{l}\text { N egociar valores, estipular } \\
\text { metas e "cobrar" das empresas } \\
\text { e do governo. }\end{array}$ & $\begin{array}{l}\text { N egociar valores compatíveis: } \\
\text { "as empresas não querem abrir } \\
\text { mão do lucro". }\end{array}$ \\
\hline NEGOCIAÇÃO & $\begin{array}{l}\text { "Brigar" para a divisão do lucro. } \\
\text { Discussão para definição de } \\
\text { parcelas. Existem diferenças entre } \\
\text { as empresas grandes, médias e } \\
\text { pequenas. As metas são, } \\
\text { normalmente, qualidade, } \\
\text { absenteísmo e produtividade. }\end{array}$ & $\begin{array}{l}\text { Contrários ao estabelecimento } \\
\text { de metas, por serem "absurdas". } \\
\text { As empresas deveriam "abrir" o } \\
\text { ivro caixa. } \\
\text { Se a empresa não tiver lucros, } \\
\text { o valor mínimo é } \mathrm{R} \$ 340,00 \text {. }\end{array}$ & $\begin{array}{l}\text { N egociar não apenas o PLR, mas } \\
\text { uma política salarial. } \\
\text { Cada empresa é uma realidade } \\
\text { diferente. Conseguir o máximo } \\
\text { para os trabalhadores. }\end{array}$ \\
\hline IMPLANTAÇÃO & $\begin{array}{l}\text { Mais fácil negociar com grandes } \\
\text { empresas. Maior dificuldade com } \\
\text { as empresas médias, pela falta de } \\
\text { estabilização financeira. As } \\
\text { pequenas implantam com prêmios } \\
\text { até de "cesta básica". }\end{array}$ & $\begin{array}{l}\text { "N ão há diferença, todas se } \\
\text { armam para lutar contra o } \\
\text { sindicato". Todas as empresas } \\
\text { implantaram. }\end{array}$ & $\begin{array}{l}\text { N ão tem nenhuma empresa } \\
\text { grande. Algumas empresas médias } \\
\text { são muito difíceis para negociar. } \\
\text { A maioria das empresas implantou. }\end{array}$ \\
\hline $\begin{array}{l}\text { SUCESSO NA } \\
\text { NEGOCIAÇÃO }\end{array}$ & $\begin{array}{l}\text { Q uando conseguiu "derrubar" o } \\
\text { empresário. }\end{array}$ & $\begin{array}{l}\text { Q uando não consegue o que } \\
\text { quer, vão para a greve. }\end{array}$ & $\begin{array}{l}\text { Ter um bom conhecimento da } \\
\text { empresa. Ter "pulso" firme na } \\
\text { negociação. Demonstrar } \\
\text { organização. }\end{array}$ \\
\hline
\end{tabular}

\begin{tabular}{|c|c|c|c|}
\hline $\begin{array}{l}\text { INÍCIO DA } \\
\text { IMPLANTAÇÃO }\end{array}$ & $\begin{array}{l}\text { As grandes negociam e as médias } \\
\text { e pequenas seguem o padrão. }\end{array}$ & $\begin{array}{l}\text { Depois de uma greve e } \\
\text { "arrastão" os químicos } \\
\text { conseguiam o valor fixo. }\end{array}$ & $\begin{array}{l}\text { As empresas sempre foram abertas } \\
\text { para negociação de PLR. } \\
\text { Maior dificuldade. Empresa S a } \\
\text { concessão é "viciada". }\end{array}$ \\
\hline $\begin{array}{l}\text { VANTAGEN S } \\
\text { PARA O } \\
\text { SIN DICATO }\end{array}$ & Apenas mais trabalho. & N enhuma vantagem. & $\begin{array}{l}\text { N ão trouxe muita vantagem. } \\
\text { O s empresários atrelam PLR } \\
\text { com índices salariais. }\end{array}$ \\
\hline $\begin{array}{l}\text { VANTAGENS } \\
\text { PARA } \\
\text { O EMPREGADO }\end{array}$ & Maior remuneração & $\begin{array}{l}\text { Mais dinheiro. } \\
\text { Mais "briga". } \\
\text { Mais justiça. }\end{array}$ & $\begin{array}{l}\text { O s empregados ficam "contentes" } \\
\text { com o "dinheiro no bolso". Existe } \\
\text { uma diminuição na arrecadação } \\
\text { de impostos o que vai gerar } \\
\text { problemas nos programas sociais. }\end{array}$ \\
\hline $\begin{array}{l}\text { VANTAGENS PARA } \\
\text { A EMPRESA }\end{array}$ & Aumento de produtividade. & $\begin{array}{l}\text { Empregados trabalham mais } \\
\text { para atingir metas "absurdas". }\end{array}$ & Mais produtividade. \\
\hline $\begin{array}{l}\text { ATITUDE } \\
\text { GEREN CIAL }\end{array}$ & $\begin{array}{l}\text { O s gerentes também recebem. } \\
\mathrm{N} \text { ão sabe se houve mudança } \\
\text { de atitude. }\end{array}$ & - & $\begin{array}{l}\text { Todos ganham. Não sabe se houve } \\
\text { mudança de atitude. }\end{array}$ \\
\hline AVALIAÇÃO & $\begin{array}{l}\text { Balanço geral das negociações das } \\
\text { grandes, médias e pequenas. } \\
\text { Verificar se o valor do prêmio } \\
\text { foi "justo". }\end{array}$ & $\begin{array}{l}\text { Verificar se o valor pago foi } \\
\text { "pouco" ou "muito". }\end{array}$ & $\begin{array}{l}\text { Acompanhamento das negociações. } \\
\text { Evolução das negociações. }\end{array}$ \\
\hline
\end{tabular}

Figura 1. Categorização do conteúdo das entrevistas - dirigentes sindicais. 
As principais constatações desta etapa foram as diferenças de programas em função da filiação sindical, a grande concentração de empresas com PLR na região entre Jacareí e Taubaté, algumas negociações realizadas com sindicatos de São Paulo e não da região, e o fato de que algumas empresas implantaram os programas antes da obrigação da Medida Provisória.

$\mathrm{N}$ a terceira etapa da pesquisa, o questionário foi aplicado em quatro empresas que se disponibilizaram, totalizando 274 respondentes.

Os dados foram submetidos a análise fatorial gerando fatores para as variáveis dependentes e independentes. Serão apresentados os principais resultados das variáveis independentes por serem mais pertinentes ao artigo.

Resultados da Análise Fatorial variável independente

A análise fatorial para variáveis independentes gerou cinco fatores que, juntos, explicam $52,50 \%$ da variância total desta análise. A variância explicada de cada fator, 0 valor acumulado e 0 engenvalue encontram-se na Tabela 1.

O bservando-se a Tabela 2, verifica-se que apenas o fator 5 (Abrangência do Programa) não apresenta diferença significativa entre as médias das empresas, o que indica que estes valores, em princípio, são compartilhados igualmente pelos respondentes das quatro empresas. Salienta-se que apenas a empresa C tem diferenciação no plano para o corpo gerencial.

O s demais fatores apresentam grau de significância de $1 \%$.

U ma análise descritiva simples das médias das empresas revela que a empresa $\mathrm{C}$ é a que apresenta maior média no fator 1 (Clareza das Informações). Isto significa que esta é a empresa que mais concorda que as informações sobre o programa são claras. Os empregados conhecem as metas e se atualizam por meio dos quadros de avisos. A empresa $C$ divulga as informações em quadros de avisos e livretos explicativos, e também por meio da comissão de empregados.

Nos fatores 2 (Espaço para participar direta e indiretamente), 3 (Metas Justas) e 4 (Critérios de N egociação), as maiores médias foram obtidas pela empresa $D$. Isto significa que os funcionários desta empresa são os que mais concordaram que existe espaço para participar direta ou indiretamente, além de identificar quem divulga - PLR e quem os representa. No fator Metas Justas, são os que mais concordam: eles notam que as metas negociadas no PLR, por representantes, são justas, são possíveis de serem atingidas e que o funcionário é informado sobre o desenvolvimento das mesmas.

Também quanto aos critérios de negociação, são os que mais concordam que os valores dos prêmios devem estar atrelados ao alcance das metas e quanto ao grau de confiança dos critérios de negociação.

Vale observar que, embora a empresa $D$ tenha apresentado a maior média, ainda assim não revela alto nível de concordância (pois encontra-se entre 0 valores 3 e 4).

A empresa $D$ vem encontrando dificuldades na negociação com o sindicato. Enquanto este pressiona por aumento do valor fixo, a empresa prefere trabalhar com metas estabelecidas.Talvez este fato esteja influenciando uma média mais elevada da empresa $D$. São mais influenciados pelo sindicato, e, além disso, a comissão é basicamente formada por elementos dos sindicatos.

\section{CONSIDERAÇÕES FINAIS}

0 primeiro dado bastante significativo é 0 fato de mais da metade das empresas médias da região já terem implantado o programa. Pode-se considerar que apenas seis implantaram os programas por liberalidade da empresa, na verdade só aderiram ao programa pós a Medida Provisória se publicada. Portanto, a intervenção

Tabela 1. Variância explicada e eingenvalue dos fatores.

\begin{tabular}{|c|c|c|c|c|}
\hline$\overline{\text { FATOR }}$ & NOME DOS FATORES & $\begin{array}{l}\text { VARINCIA } \\
\text { EXPLICADA }\end{array}$ & $\begin{array}{c}\text { VARINCIA EXPLICADA } \\
\text { ACUMULADA }\end{array}$ & EINGENVALUE \\
\hline 1 & Clareza nas informações & 29,0 & 29,0 & 6,381 \\
\hline 2 & Espaço para participar direta e indiretamente & 7,0 & 36,0 & 1,534 \\
\hline 3 & Metas justas & 6,3 & 42,3 & 1,391 \\
\hline 4 & Critérios de negociação & 5,4 & 47,7 & 1,193 \\
\hline 5 & Abrangência do programa & 4,7 & 52,5 & 1,038 \\
\hline
\end{tabular}

Tabela 2. Resultado da análise de variância por empresa: variável independente.

\begin{tabular}{lccccc}
\hline \multirow{2}{*}{ FATOR } & \multicolumn{2}{c}{ MÉDIAS } & \multicolumn{2}{c}{ RESULTADO DA AN OVA } \\
\cline { 2 - 6 } N ÃO SIG & EMPRESA A & EMPRESA B & EMPRESA C & EMPRESA D & SIG/ \\
1. Clareza nas informações & 3,20 & 3,15 & 3,78 & 3,67 & S.*** \\
2. Espaço para participar direta e & 2,76 & 3,15 & 3,29 & 3,64 & $S^{* * *}$ \\
$\quad$ indiretamente & 2,69 & 2,75 & 3,40 & 3,76 & S*** \\
3. Metas justas & 2,40 & 3,40 & 3,06 & 3,95 & S*** \\
4. Critérios de negociação & 3,26 & 3,61 & 3,43 & 3,53 & NS \\
5. Abrangência do Programa & &
\end{tabular}


governamental mobilizou as empresas e sindicatos a negociarem os programas de PLR, confirmando dados das pesquisas da Fipe (1998)(3) e revista LIDA (1999).(1)

O utra observação significativa é que a orientação política sindical interfere, e quase determina que os programas sejam negociados com as empresas com base em metas ou valores fixos. A empresa D da amostra, por exemplo, apesar de filiada ao sindicato dos metalúrgicos, adotou os valores fixos, conquistados pelo sindicato dos químicos de orientação PSTU. As demais orientações sindicais, articuladas ou neutras, são mais flexíveis para negociarem programas tendo como base um plano de metas.

Constatou-se, também, que as empresas procuram negociar indicadores e metas compatíveis com suas prioridades, o que vai de encontro a uma das expectativas da legislação que prevê, como resultado dessa intervenção, o aumento da produtividade e da qualidade nas empresas.

A orientação sindical tem que ser levada em consideração, para compreensão dos programas negociados pelas empresas.

Talvez se possa inferir que as empresas com participação mais efetiva dos sindicatos negociem metas mais fáceis de serem atingidas, como a redução do absenteísmo e acidentes de trabalho, e também da organização do trabalho segundo as especificidades de cada empresa. U ma das dificuldades apontadas pelo dirigente sindical de orientação moderada era a de que os representantes do sindicato, durante as negociações, não tinham informações e conhecimento suficientes para identificar se as metas estavam super dimensionadas. Por meio dos resultados dos programas é que eles se orientam para as próximas negociações. Por serem metas gerais e não voltadas para as particularidades da empresa, os empregados podem passar a considerar o programa e resultados como uma recompensa financeira por comportamento adequado, e não por decorrência e seu envolvimento com as metas e objetivos do seu trabalho e da sua empresa.

\section{REFERÊNCIAS}

1 LIDA. Ao alcance de todos. Revista do Ministério do Trabalho, p 82-87, jan. 1999.

2 DIEESE. LInha Bancários. 0 programa de remuneração variável do itaú (AGIR): alguns comentários. São Paulo : 1999. Disponível em: < http://www pbancários.com.bd/economia/diees1.htm>. Acesso em: 9 ago. 2006.

3 FIPE. Boletim de Informações, ago. 1998. Disponível em < http//www.fipe.org.br>. Acesso em: dez. 2000.

4 GON ÇALVES, R. Participação dos trabalhadores nos lucros ou resultados das empresas. Texto para discussão n. 42, BN DES, 1996.

5 FLEURY, A. \& HUMPHREY, J. Estratégias de recursos humanos em empresas que buscam qualidade e produtividade. Seminário "Desenvolvimento Econômico, Investimento Mercado de Trabalho e Distribuição de Renda". Rio de Janeiro: BNDES, 1992.

6 SIN DICATO DOS TRABALHAD O RES DO ABC. Participação nos lucros e ou nos resultados das empresas: a visão dos metalúrgicos do ABC. Fev. 1998.

Recebido em: 09/02/06

Aceito em: 28/07/06

Proveniente de: CONGRESSO AN UAL DA ABM, 60., 2005, Belo Horizonte, MG. São Paulo : ABM, 2005. 